\title{
Corrigendum to "Correlation between First and Second Trimester Uterine Artery Doppler Velocimetry and Placental Bed Histopathology"
}

\author{
Murat Akbaş (iD, ${ }^{1}$ Cihat Şen (iD, ${ }^{2}$ and Zerrin Calay ${ }^{3}$ \\ ${ }^{1}$ Department of Obstetrics and Gynecology, Okmeydani Research Hospital, Istanbul 34382, Turkey \\ ${ }^{2}$ Department of Obstetrics and Gynecology, Cerrahpasa Faculty of Medicine, Istanbul University, Istanbul 34098, Turkey \\ ${ }^{3}$ Department of Pathology, Cerrahpasa Faculty of Medicine, Istanbul University, Istanbul 34098, Turkey
}

Correspondence should be addressed to Murat Akbaş; drmuratakbas@yahoo.com.tr

Received 2 September 2019; Accepted 24 October 2019; Published 29 May 2020

Copyright (c) 2020 Murat Akbaş et al. This is an open access article distributed under the Creative Commons Attribution License, which permits unrestricted use, distribution, and reproduction in any medium, provided the original work is properly cited.

In the article titled "Correlation between First and Second Trimester Uterine Artery Doppler Velocimetry and Placental Bed Histopathology" [1], there were missing cases in Tables 1 and 2 .

TABle 1: Demographic and clinical characteristics of the study population.

\begin{tabular}{lccc}
\hline & $\begin{array}{c}\text { Normal placental } \\
\text { histology group }(n=100)\end{array}$ & $\begin{array}{c}\text { Abnormal placental } \\
\text { histology group }(n=16)\end{array}$ & $\begin{array}{c}P \\
\text { value }\end{array}$ \\
\hline Age & $27.8 \pm 4.5$ & $28.8 \pm 3.5$ & 0.420 \\
Parity & $1(0-6)$ & $0(0-3)$ & 0.499 \\
$\begin{array}{l}\text { Birth } \\
\text { weight }\end{array}$ & $\mathbf{3 2 0 2 ( 4 1 7 )}$ & $\mathbf{2 9 6 4 ( \pm 4 3 5 )}$ & $\mathbf{0 . 0 0 7}$ \\
$\begin{array}{l}\text { Birth } \\
\text { week }\end{array}$ & $38(35-41)$ & $38(32-40)$ & 0.188 \\
\hline
\end{tabular}

Values are expressed as median (range) or mean (standard deviation).

TABLe 2: Statistical evaluation of Doppler findings.

\begin{tabular}{lccc}
\hline & $\begin{array}{c}\text { Normal placental } \\
\text { histology group } \\
(n=100)\end{array}$ & $\begin{array}{c}\text { Abnormal placental } \\
\text { histology group } \\
(n=16)\end{array}$ & $\begin{array}{c}P \\
\text { value }\end{array}$ \\
\hline 1st trimester PI & $1.73 \pm 0,39$ & $1.93 \pm 0,36$ & 0.067 \\
1st trimester RI & $0.71 \pm 0,07$ & $0.75 \pm 0,07$ & 0.056 \\
1st trimester & $\mathbf{\% 4 5}$ & $\mathbf{\% 1 0 0}$ & $<\mathbf{0 . 0 0 1}$ \\
notch & $\mathbf{1 . 0 5} \pm \mathbf{0 , 3 1}$ & $\mathbf{1 . 4 9} \pm \mathbf{0 , 1 6}$ & $<\mathbf{0 . 0 0 1}$ \\
2nd trimester PI & $\mathbf{0 . 5 5} \pm \mathbf{0 , 0 7}$ & $\mathbf{0 . 6 6} \pm \mathbf{0 , 0 4}$ & $<\mathbf{0 . 0 0 1}$ \\
2nd trimester RI & $\mathbf{0 1 4}$ & $\mathbf{0 1 0 0}$ & $<\mathbf{0 . 0 0 1}$ \\
2nd trimester & notch & &
\end{tabular}

Values are expressed as mean \pm standard deviation.
After recalculation of the statistical analysis, the following sections should be corrected.

The fourth paragraph in the results section, "Uterine artery PI and RI mean values were 1,42 and 0,67 in abnormal placental histology group. For normal histology group, they were $12,1,02$, and $0,56 \%$ in order $(P<0.01)$." should be changed to "Uterine artery PI and RI mean values were 1.49 and 0.66 in the abnormal placental histology group. For the normal histology group, they were 1.05 and 0.55 in order $(P<0.01)$."

The second paragraph in the discussion section, "But in our study there was no significant difference among two groups for birth weights." should be changed to "In concordance with the previous finding, we reported significant difference among the two groups for birth weight."

The third paragraph in the discussion section, "In the present study, bilateral notching was found in $45 / 100$ of the normal histology group in first trimester and $12 / 100$ of the normal histology group in second trimester. The ratio was $16 / 16$ of the abnormal placental histology group $(P<0.01)$. In the normal histology group, mean value of PI was $1,02 \pm 0,31$ and mean value of RI was $0,56 \pm 0,08$ at second trimester. In the abnormal placental histology group, means were $1,42 \pm 0,21$ and $0,67 \pm 0,05$, respectively." should be changed to "In the present study, bilateral notching was found in $45 / 100$ of the normal histology group in the first trimester and $14 / 100$ of the normal histology group in the second trimester. The ratio was 16/ 
16 of the abnormal placental histology group $(P<0.001)$. In the normal histology group, the mean value of PI was $1.05 \pm 0.32$, and the mean value of RI was $0.55 \pm 0.07$ at the second trimester. In the abnormal placental histology group, mean values were $1.49 \pm 0.16$ and $0.66 \pm 0.04$, respectively."

The fourth paragraph in the discussion section, "In our study, in first trimester, mean value of PI was 1,64 $\pm 0,45$ and mean value of RI was $0,70 \pm 0,08$ in the normal group. Means were $1,91 \pm 0,52$ and $0,73 \pm 0,1$ in the abnormal placental histology group." should be changed to "In our study, in the first trimester, the mean value of PI was $1.73 \pm 0.39$, and the mean value of RI was $0.71 \pm 0.07$ in the normal group. Mean values were $1.93 \pm 0.36$ and $0.75 \pm 0.07$ in the abnormal placental histology group."

Tables 1 and 2 should be corrected as shown above.

We also wish to add the following acknowledgement that was missing in the original article: We thank Professor Kutsiye Pelin Öcal, Istanbul University, Turkey for reviewing and commenting on the manuscript.

\section{References}

[1] M. Akbaş, C. Şen, and Z. Calay, "Correlation between first and second trimester uterine artery Doppler Velocimetry and placental bed Histopathology," International Scholarly Research Notices, vol. 2014, Article ID 890534, 6 pages, 2014. 